Cite this article as: BMJ, doi:10.1136/bmj.38814.696493.AE (published 28 April 2006)

Research

\title{
Cerebral emboli as a potential cause of Alzheimer's disease and vascular dementia: case-control study
}

Nitin Purandare, Alistair Burns, Kevin J Daly, Jayne Hardicre, Julie Morris, Gary Macfarlane, Charles McCollum

\begin{abstract}
Objective To compare the occurrence of spontaneous cerebral emboli and venous to arterial circulation shunts in patients with Alzheimer's disease or vascular dementia and controls without dementia.

Design Cross sectional case-control study.

Setting Secondary care old age psychiatry services, Manchester. Participants 170 patients with dementia (85 with Alzheimer's disease, 85 with vascular dementia) and 150 age and sex matched controls. Patients on anticoagulant treatment, patients with severe dementia, and controls with marked cognitive impairment were excluded.

Main outcome measures Frequencies of detection of spontaneous cerebral emboli during one hour monitoring of the middle cerebral arteries with transcranial Doppler and venous to arterial circulation shunts by a transcranial Doppler technique using intravenous microbubbles as an ultrasound contrast.

Results Spontaneous cerebral emboli were detected in 32 $(40 \%)$ of patients with Alzheimer's disease and 31 (37\%) of those with vascular dementia compared with just 12 each (15\% and $14 \%$ ) of their controls, giving significant odds ratios adjusted for vascular risk factors of 2.70 (95\% confidence interval 1.18 to 6.21) for Alzheimer's disease and 5.36 (1.24 to 23.18) for vascular dementia. These spontaneous cerebral emboli were not caused by carotid disease, which was equally frequent in dementia patients and their controls. A venous to arterial circulation shunt indicative of patent foramen ovale was found in 27 (32\%) Alzheimer's disease patients and 25 (29\%) vascular dementia patients compared with $19(22 \%)$ and 17 (20\%) controls, giving non-significant odds ratios of 1.57 (0.80 to 3.07 ) and 1.67 (0.81 to 3.41 ).

Conclusion Spontaneous cerebral emboli were significantly associated with both Alzheimer's disease and vascular dementia. They may represent a potentially preventable or treatable cause of dementia.
\end{abstract}

\section{Introduction}

Alzheimer's disease and vascular dementia account for $80 \%$ of all dementias; evidence exists of considerable overlap between the two, epidemiologically, clinically, and histopathologically. ${ }^{1}$ Vascular risk factors such as hypertension, hypercholesterolaemia, diabetes, and smoking are implicated in both dementias, but the underlying pathophysiology remains uncertain. ${ }^{2}$ Both Alzheimer's disease and vascular dementia are associated with carotid atherosclerosis, even in patients without symptoms of cerebrovascular disease. ${ }^{3}$
Carotid disease is one potential source of spontaneous cerebral emboli (SCE). Embolic signals will be detected on transcranial Doppler of the middle cerebral arteries, if monitored over several hours, in most patients with symptomatic or severe stenosis. ${ }^{4}$ A large embolus may cause stroke or transient ischaemic attack, but repeated small asymptomatic emboli over many months or years may cause progressive cerebral damage. Microemboli entering the cerebral circulation during open heart surgery or carotid surgery have been associated with cognitive deficits and in particular memory loss. ${ }^{5-8}$

Valvular heart disease, atrial fibrillation, and paradoxical embolisation of venous emboli into the arterial circulation are other potential sources of SCE. ${ }^{910}$ Atrial fibrillation has been shown to be a risk factor for dementia, ${ }^{11}$ but the significance of paradoxical embolisation has not been explored. Paradoxical embolisation has recently been found to be associated with cryptogenic stroke in young adults, postoperative confusion after hip replacement, migraine, decompression sickness in scuba divers, and transient global amnesia. ${ }^{12-15}$ As venous emboli may enter the arterial circulation through a patent foramen ovale, other atrial-ventricular septal defects, or pulmonary arteriovenous fistulas, we prefer the term "venous to arterial circulation shunt" (v-aCS) to either patent foramen ovale or "right to left heart shunt."

We standardised a minimally invasive transcranial Doppler technique to detect v-aCS and did a pilot study in patients with Alzheimer's disease or vascular dementia. ${ }^{16}{ }^{17}$ SCE and v-aCS were more common in dementia patients than in community controls. We therefore set up this study to explore definitively the frequencies of SCE, carotid artery disease, and v-aCS in Alzheimer's disease and vascular dementia.

\section{Methods}

This was a case-control study, in which we individually matched patients with Alzheimer's disease or vascular dementia to controls of the same sex and age. All participants gave written, informed consent, and, in the case of patients with dementia, their carers were involved in the consent process.

\section{Study subjects}

Patients-We recruited patients who satisfied the Diagnostic and Statistical Manual of Mental Disorders, fourth edition (DSM-IV) criteria for dementia through a network of old age psychiatrists in Greater Manchester. We used the National Institute of Neurological and Communicative Disorders and Stroke-

An appendix is on bmj.com 
Alzheimer's Disease and Related Disorders Association (NINCDS-ADRDA) criteria for Alzheimer's disease and the National Institute of Neurological Disorders and StrokeAssociation Internationale pour la Recherche et l'Enseignement en Neurosciences (NINDS-AIREN) criteria for vascular dementia. ${ }^{18}$ We used neuroimaging by computed tomography or magnetic resonance imaging to help to allocate the diagnosis of "probable" Alzheimer's disease or "probable" vascular dementia.

Controls-We individually matched controls to dementia patients by sex, age, and geographical area of residence. For each patient, we identified six people from the same general practice list of the same sex and closest in age to the index patient. We sent study information to all six potential controls, and, from those replying, the researcher saw the closest in age to check eligibility and obtain consent. If a potential control was ineligible or refused consent, we approached the next closest in age. Controls were never duplicated within the same dementia group, but when we had difficulties with general practice or individual consent, we examined potential controls not recruited previously for another patient in the same or neighbouring practice and recruited the closest match by age. For each case, the respective control was from the same general practice $(62 / 170,36 \%)$ or from a general practice in a similar socioeconomic area of Greater Manchester (108/170, 64\%).

Exclusion criteria-We excluded patients if they had a minimental state examination score of less than 10 (severe dementia, unlikely to be able to participate). ${ }^{20}$ We excluded controls if they had a diagnosis of dementia or scored less than 24 on the minimental state examination (suggesting significant cognitive impairment or undiagnosed dementia). We excluded patients and controls who had severe aphasia, had an inadequate transtemporal window for transcranial Doppler insonation of the middle cerebral arteries, or were taking anticoagulant drugs.

\section{Study assessments}

We collected details on cardiovascular risk factors at interview with patients and their carers or with controls. We examined the psychiatric notes to verify medical and psychiatric history for cases. An independent clinician used the above criteria to diagnose Alzheimer's disease and vascular dementia. Technologists in the Vascular Studies Unit at South Manchester University Hospital independently investigated SCE, carotid disease, and $\mathrm{v}$-aCS; they were not told the diagnosis but obviously could not be kept fully blind to dementia.

\section{Spontaneous cerebral emboli}

We detected SCE, thought to be particulate, by continuous transcranial Doppler insonation of the middle cerebral arteries through the transtemporal window for one hour. This was done before transcranial Doppler investigation of v-aCS, to avoid detecting air microemboli. The consensus on microembolus detection by transcranial Doppler advises that studies should report key technical parameters used in embolus detection (see appendix on bmj.com). ${ }^{21}$ We used a Neuroguard (software version 2.9, Medasonics) transcranial Doppler with a $2 \mathrm{MHz}$ pulsed wave Doppler probe. The output was recorded on digital tape for subsequent blind analysis by two trained vascular technologists. The same trained vascular laboratory staff observed patients throughout each one hour session and recorded any movement so that artefacts could be identified. We used international consensus criteria to define emboli: "Embolic signals should be transient (lasting $<300$ milliseconds), at least 3 $\mathrm{dB}$ higher than the background blood flow signal, unidirectional, within the Doppler spectrum, and accompanied by an audible 'snap', 'chirp', or 'moan'."'22

Transcranial Doppler monitoring for SCE was unilateral (middle cerebral arteries with the best signal) in $111(65 \%)$ of 170 dementia patients and $122(72 \%)$ of 170 of their controls $(\mathrm{P}=0.24)$. We found no association between the number of middle cerebral arteries monitored and detection of either v-aCS or SCE. Furthermore, adjustment for type of monitoring in the logistic regression analyses resulted in almost identical results to those obtained without adjustment.

\section{Carotid artery disease}

We used colour duplex ultrasound (ATL "Ultramark 9") to image carotid disease and used established criteria to calculate the severity of stenosis from the peak systolic velocity in the internal carotid arteries. ${ }^{23}$

\section{Detection of venous to arterial circulation shunts}

We used a standardised transcranial Doppler technique to detect $\mathrm{v}$-aCS, with insonation of the middle cerebral arteries and intravenous injection of an emulsion of air microbubbles in saline as an ultrasound contrast medium. This is a minimally invasive technique that has been shown to be sensitive and specific to patent foramen ovale. ${ }^{24-26}$

An 18 French cannula was inserted into an antecubital vein with the participant lying semirecumbent. Saline $(8 \mathrm{ml})$, air (1 $\mathrm{ml})$, and the patient's own blood $(0.5 \mathrm{ml})$ as an emulsificant were mixed vigorously 12 times between two $10 \mathrm{ml}$ syringes through a three way tap to create a microbubble emulsion that was then rapidly injected intravenously. Each emulsion, separated by intervals of at least one minute, was injected twice each while resting quietly; with provocation by coughing repeatedly during injection and for a further five seconds; and with provocation by a standardised Valsalva manoeuvre, blowing into a mouthpiece to maintain a pressure of $40 \mathrm{~mm} \mathrm{Hg}$ immediately on injection and released by exhaling five seconds later.

Two trained vascular technologists counted microbubble embolic signals from the middle cerebral arteries. The study coordinator, who was blind to case or control status, verified the results by subsequent analysis of data tapes. The procedure was stopped if $>50$ microbubbles were detected at rest or $>80$ were detected after provocation. For participants who had unilateral monitoring of middle cerebral arteries, we duplicated the number of embolic signals to equate to bilateral monitoring. We based the criteria for "significant" v-aCS on our study comparing transcranial Doppler with the diagnosis of patent foramen ovale on transoesophageal echocardiography. ${ }^{16}$ As we use a rigorously standardised protocol for provocation testing, we prefer the following definition of significant $\mathrm{v}$-aCS to that of the International Consensus Committee. ${ }^{27}$ We defined a significant v-aCS (criteria for patent foramen ovale) as transcranial Doppler detection of $\geq 15$ embolic signals within 12 cardiac cycles of contrast injection. ${ }^{16}$ We defined a "major" v-aCS as either $>50$ embolic signals at rest or $>10$ at rest and $>80$ after provocation by coughing or Valsalva manoeuvre.

\section{Power and statistical analysis}

We found a v-aCS (any v-aCS) in 18 (51\%) of the first 35 patients examined in our pilot study and used this as the basis for the power calculations. ${ }^{17}$ As we would expect to detect a patent foramen ovale in $22-24 \%$ of normal people, ${ }^{28}$ a sample size of 85 Alzheimer's disease and 85 vascular dementia case-control pairs would have over $80 \%$ power to detect differences of $25 \%$ or more between cases and controls, with an average odds ratio of 2.4, 


\begin{tabular}{|c|c|c|}
\hline Stage of recruitment & Cases & Controls \\
\hline Consented & 255 & 186 \\
\hline Excluded or withdrawn & 49 & 19 \\
\hline Taking oral anticoagulant & 2 & NA \\
\hline $\begin{array}{l}\text { Did not satisfy Alzheimer's disease or vascular } \\
\text { dementia criteria }\end{array}$ & 4 & NA \\
\hline No acoustic window for transcranial Doppler & 29 & 14 \\
\hline No adequate antecubital vein & - & 1 \\
\hline MMSE score $<24$ for controls & NA & 2 \\
\hline Fulfilled study criteria & 170 & 150 \\
\hline $\begin{array}{l}\text { Controls used for both Alzheimer's disease and } \\
\text { vascular dementia patients }\end{array}$ & NA & 20 \\
\hline Case-control pairs in matched analysis & 170 & 170 \\
\hline
\end{tabular}

MMSE=mini-mental state examination; NA=not applicable.

determined using a McNemar's test with a discordant pair rate ranging between $50 \%$ and 70\%. We used nQuery Advisor 5.0 to derive the power calculations and SPSS release 11.5 and Stata version 8.0 to do statistical analyses.

We used McNemar's test, paired $t$ test, and conditional logistic regression analysis to compare dementia patients with their matched controls for cardiovascular risk factors, the occurrence of SCE, carotid disease, and v-aCS. We used $\chi^{2}$ tests and two sample $t$ tests to assess the relation between SCE positivity and cardiovascular risk factors.

\section{Results}

We recruited a total of 170 patients with dementia (85 with Alzheimer's disease and 85 with vascular dementia) and 150 controls (tables 1 and 2). These included 22 dementia patients (17 Alzheimer's disease, 5 vascular dementia) and 15 controls reported in the pilot study. ${ }^{17}$ Twenty controls were used for both Alzheimer's disease and vascular dementia patients. The mean age difference between cases and controls was 0.12 (SD 1.74) years.

\section{Risk factors for cerebrovascular disease}

Patients with Alzheimer's disease and vascular dementia had a similar profile of cardiovascular risk factors to their respective controls (table 3), except for the more frequent history of stroke or transient ischaemic attack in vascular dementia patients compared with their controls (odds ratios 8.5 (95\% confidence interval 2.0 to 36.8 ) for stroke and 21.5 (5.2 to 88.7) for transient ischaemic attack). Both Alzheimer's disease and vascular dementia patients also had lower body mass index than their controls. Compared with Alzheimer's disease patients, those with vascular dementia were more likely to have a history of stroke $(\mathrm{P}<0.001)$, transient ischaemic attack $(\mathrm{P}<0.001)$, antiplatelet drugs $(\mathrm{P}<0.001)$, and hypertension $(\mathrm{P}=0.01)$ and lower high density lipoprotein cholesterol concentrations $(\mathrm{P}=0.03)$. These factors are all likely to lead a clinician to diagnose vascular dementia or, in the case of antiplatelet drugs, a consequence of that diagnosis.

\section{Spontaneous cerebral emboli}

In a single hour of transcranial Doppler monitoring, we detected SCE in $32(40 \%)$ Alzheimer's disease and 31 (37\%) vascular dementia patients compared with only $12(15 \%)$ and $12(14 \%)$ respectively of their controls (table 4 ). We detected two or more SCE in 17 (21\%) Alzheimer's disease and 18 (21\%) vascular dementia patients, and in $9(11 \%)$ and $8(9 \%)$ of their respective controls. The median number of SCE when present was 2 (interquartile range 1-2) for Alzheimer's disease, 2 (1-3) for vascular dementia, and 1 (1-5) for controls. The odds ratio for SCE was 3.22 (1.52 to 6.81) in Alzheimer's disease and 4.80 (1.83 to 12.58) in vascular dementia. After exclusion of participants reported in the pilot study, the odds ratio was 2.88 (1.29 to 6.43) for Alzheimer's disease (61 case-control pairs, 26 (43\%) v $11(18 \%)$, $\mathrm{P}=0.01$ ) and 4.00 (1.50 to 10.66 ) for vascular dementia (70 casecontrol pairs, $27(38 \%) v 12(17 \%), \mathrm{P}=0.006)$. The odds ratios for SCE (all participants) remained similar and highly significant at 2.70 (1.18 to 6.21) for Alzheimer's disease and 5.36 (1.24 to 23.18) for vascular dementia after adjustment for cardiovascular risk factors.

\section{Carotid disease}

We detected moderate or severe $(>50 \%)$ carotid stenosis in either internal carotid artery in 7/82 (8\%) Alzheimer's disease patients and 20/78 (26\%) vascular dementia patients compared with 13/82 (16\%) and 26/78 (20\%) of their respective controls $(\mathrm{P}=0.14$ and $\mathrm{P}=1.0)$. We detected severe $(>70 \%)$ carotid stenosis in none of the Alzheimer's disease patients, $6(8 \%)$ vascular dementia patients, and $5(6 \%)$ of both sets of controls $(\mathrm{P}=0.06$ and $\mathrm{P}=0.74$ ).

\section{Venous to arterial circulation shunts}

We detected a "significant" v-aCS in 27 (32\%) Alzheimer's disease patients and $25(29 \%)$ vascular dementia patients compared with $19(22 \%)$ and $17(20 \%)$ of their respective controls. The odds ratio was 1.57 (0.80 to 3.07) for Alzheimer's disease and 1.67 (0.81 to 3.41) for vascular dementia. Excluding participants reported in the pilot study gave odds ratios of 1.58 (0.77 to 3.26) for Alzheimer's disease (64 case-control pairs, 23 $(36 \%)$ v $16(25 \%), \mathrm{P}=0.21)$ and $1.50(0.72$ to 3.11$)$ for vascular dementia (72 case-control pairs, $22(31 \%) v 16(22 \%), \mathrm{P}=0.28)$. We detected a "major" v-aCS in 16 (19\%) Alzheimer's disease patients and $13(15 \%)$ vascular dementia patients compared with $10(12 \%)$ and $12(14 \%)$ of their respective controls $(\mathrm{P}=0.21$ and $\mathrm{P}=0.83$ ).

\section{SCE and cardiovascular risk factors}

As expected, SCE were associated with all the major cardiovascular risk factors in controls (table 5). We found no such association in dementia patients, implying that SCE may be universal in dementia. We found a greater than $70 \%$ carotid stenosis in $4(19 \%)$ of $21 \mathrm{SCE}$ positive controls compared with only 6 $(5 \%)$ of 124 controls who were SCE negative $(\mathrm{P}=0.02)$, but the difference was not significant in patients with dementia. SCE

Table 2 Details of cases and controls. Values are numbers (percentages) unless stated otherwise

\begin{tabular}{|c|c|c|c|c|}
\hline \multirow{2}{*}{ Characteristic } & \multicolumn{2}{|c|}{ Alzheimer's disease } & \multicolumn{2}{|c|}{ Vascular dementia } \\
\hline & Cases $(n=85)$ & Controls $(n=85)$ & Cases $(n=85)$ & Controls $(n=85)$ \\
\hline Male sex & $43(51)$ & $43(51)$ & $45(53)$ & $45(53)$ \\
\hline Mean (SD) age (years) & $75.2(7.6)$ & $75.4(7.2)$ & $77.5(6.3)$ & $77.6(6.2)$ \\
\hline "Probable" dementia & $73(86)$ & NA & $60(71)$ & NA \\
\hline "Possible" dementia & $12(14)$ & NA & $25(29)$ & NA \\
\hline Mean (SD) MMSE score & $21.8(4.5)$ & $28.6(1.4)$ & $21.4(5.1)$ & $28.5(1.4)$ \\
\hline
\end{tabular}

MMSE=mini-mental state examination; NA=not applicable. 
Table 3 Cardiovascular risk factors. Values are numbers (percentages) unless stated otherwise

\begin{tabular}{|c|c|c|c|c|c|c|c|c|c|}
\hline \multirow[b]{2}{*}{ Risk factor } & \multicolumn{3}{|c|}{ Alzheimer's disease } & \multicolumn{3}{|c|}{ Vascular dementia } & \multicolumn{3}{|c|}{ All dementia } \\
\hline & Cases $(n=85)$ & $\begin{array}{c}\text { Controls } \\
(\mathrm{n}=85)\end{array}$ & $P$ value & Cases $(n=85)$ & Controls $(\mathrm{n}=85)$ & $P$ value & Cases $(n=170)$ & Controls $(n=150)$ & $P$ value \\
\hline Hypertension & $25(29)$ & $31(36)$ & 0.29 & $41(48)$ & $34(40)$ & 0.31 & $66(39)$ & $57(38)$ & 0.88 \\
\hline Myocardial infarction & $6(7)$ & $6(7)$ & 1.0 & $6(7)$ & $8(9)$ & 0.57 & $12(7)$ & $13(9)$ & 0.59 \\
\hline Angina & $9(11)$ & $15(18)$ & 0.17 & $12(14)$ & $9(11)$ & 0.49 & $22(13)$ & $23(15)$ & 0.54 \\
\hline Stroke & $1(1)$ & $5(6)$ & 0.12 & $18(21)$ & $3(4)$ & 0.004 & $19(11)$ & $8(5)$ & 0.06 \\
\hline $\begin{array}{l}\text { Transient ischaemic } \\
\text { attack }\end{array}$ & $4(5)$ & 7 (8) & 0.37 & $49(58)$ & $8(9)$ & $<0.001$ & $53(31)$ & $12(8)$ & $<0.001$ \\
\hline $\begin{array}{l}\text { Peripheral vascular } \\
\text { disease }\end{array}$ & $19(22)$ & $16(19)$ & 0.60 & 19 (22) & $22(26)$ & 0.58 & $38(22)$ & $33(22)$ & 0.96 \\
\hline Diabetes & $2(2)$ & $2(2)$ & 1.0 & $8(9)$ & $6(7)$ & 0.53 & $10(6)$ & $7(5)$ & 0.63 \\
\hline Smoking (current) & $15(18)$ & $10(12)$ & 0.39 & $12(14)$ & $11(13)$ & 0.35 & $27(16)$ & $21(14)$ & 0.56 \\
\hline Antiplatelet drugs* & $22(26)$ & $16(19)$ & 0.29 & $51(60)$ & $33(39)$ & 0.007 & $73(43)$ & $44(29)$ & 0.012 \\
\hline Mean (SD) BMI & $24.0(4.4)$ & $26.0(4.0)$ & 0.005 & $24.3(4.2)$ & $25.9(3.7)$ & 0.026 & $24.2(4.3)$ & $25.6(3.9)$ & 0.001 \\
\hline \multicolumn{10}{|c|}{ Mean (SD) blood pressure $(\mathrm{mm} \mathrm{Hg})$ : } \\
\hline Systolic & $141.1(25.9)$ & $146.0(23.4)$ & 0.26 & $142.5(28.2)$ & $140.8(21.4)$ & 0.70 & $142.1(27.1)$ & $144.7(23.0)$ & 0.38 \\
\hline Diastolic & $75.1(13.1)$ & $79.4(14.7)$ & 0.10 & $76.2(13.7)$ & $77.2(14.0)$ & 0.64 & $76.1(13.8)$ & $78.4(14.3)$ & 0.16 \\
\hline \multicolumn{10}{|c|}{ Mean (SD) lipid concentrations (mmol/l): } \\
\hline Cholesterol & $5.46(0.97)$ & $5.55(1.17)$ & 0.57 & $5.19(1.20)$ & $5.30(0.99)$ & 0.48 & $5.34(1.09)$ & $5.41(1.06)$ & 0.59 \\
\hline HDL cholesterol & $1.41(0.40)$ & $1.46(0.55)$ & 0.46 & $1.29(0.37)$ & $1.39(0.38)$ & 0.11 & $1.35(0.39)$ & $1.42(0.47)$ & 0.13 \\
\hline LDL cholesterol & $3.27(0.85)$ & $3.28(0.99)$ & 0.93 & $3.13(0.96)$ & $3.09(0.83)$ & 0.73 & $3.23(0.91)$ & $3.19(0.93)$ & 0.72 \\
\hline Triglycerides $†$ & $1.38(0.9-1.8)$ & $1.66(1.2-2.2)$ & 0.04 & $1.45(1.0-2.0)$ & $1.57(1.1-2.3)$ & 0.33 & $1.42(1.0-1.9)$ & $1.65(1.2-2.3)$ & 0.008 \\
\hline
\end{tabular}

$\mathrm{BMI}=$ body mass index; HDL=high density lipoprotein; LDL=low density lipoprotein.

*Mainly aspirin, except clopidogrel (one vascular dementia), dipyridamole (one vascular dementia, one vascular dementia control), aspirin plus dipyridamole (two vascular dementia). †Geometric mean (interquartile range).

were not significantly associated with v-aCS in either patients or controls.

\section{Discussion}

This study shows that spontaneous cerebral emboli are significantly more common in patients with dementia than in age and sex matched population controls. The frequency of SCE was similar in Alzheimer's disease and vascular dementia, which may explain the similarity in risk factors between these two dementias with differing final pathology.

\section{Frequency and sources of SCE}

SCE may occur in carotid disease, especially in patients with symptomatic or severe disease; with several hours of monitoring, SCE can be detected in more than half of patients with $>70 \%$ stenosis. ${ }^{49}$ Remarkably, the frequency of SCE during a single hour of monitoring in patients with dementia was $37-40 \%$, raising the possibility that SCE would be detected in many more patients if they were monitored over several hours. As we found no significant association between carotid disease and SCE in these dementia patients, carotid atherosclerosis seems to be an unlikely source for most SCE in dementia. None of the study participants had clinically significant or uncontrolled atrial fibrillation, and we excluded everyone taking anticoagulant drugs. Undiagnosed atrial fibrillation would not explain the presence of emboli in almost $40 \%$ of dementia patients.
In controls, in whom SCE were less frequent, we found the expected and statistically significant association between cardiovascular risk factors and SCE. In dementia, SCE were much more common and were not associated with cardiovascular risk factors. Many of our emboli negative patients might have had emboli detected if they were monitored for longer, and no association with cardiovascular risk factors would exist if SCE were universal in dementia patients. Alternatively, other mechanisms such as inflammation could be involved in the pathophysiology of both SCE and dementia.

\section{Are some SCE paradoxical?}

We had insufficient evidence to conclude that any real difference existed in the frequencies of "significant" venous to arterial circulation shunt (patent foramen ovale) between patients with dementia and controls. Our study was not sufficiently powered, as we based the original power calculations on a pilot study done before v-aCS criteria for patent foramen ovale (significant v-aCS) had been worked out. ${ }^{16}$ Percutaneous closure of patent foramen ovale is used increasingly for atrial septal aneurysms with multiple embolic events. The risks and benefits of patent foramen ovale closure are also being explored in other conditions, such as migraine, and in divers. ${ }^{30}$

\section{Limitations}

A possible limitation of our study was that vascular technologists could not be blinded to the case or control status of participants.

Table 4 Spontaneous cerebral emboli (SCE)

\begin{tabular}{|c|c|c|c|c|c|c|c|}
\hline \multirow{2}{*}{ Detection of SCE } & \multicolumn{2}{|c|}{ Alzheimer's disease } & \multicolumn{2}{|c|}{ Vascular dementia } & \multicolumn{3}{|c|}{ All dementia } \\
\hline & Cases $(\mathrm{n}=\mathbf{8 0})$ & Controls $(n=80)$ & Cases $(n=83)$ & Controls $(n=83)$ & Cases & $(n=167)$ & Controls $(n=145)$ \\
\hline No (\%) SCE positive* & $32(40)$ & $12(15)$ & $31(37)$ & $12(14)$ & 65 & (39) & 21 (15) \\
\hline Odds ratio $(95 \% \mathrm{Cl}) ; \mathrm{P}$ value & \multicolumn{2}{|c|}{3.22 (1.52 to 6.81 ); 0.002} & \multicolumn{2}{|c|}{4.80 (1.83 to 12.58$) ; 0.001$} & \multicolumn{3}{|c|}{$3.76(2.15,6.57) ;<0.001$} \\
\hline Adjusted odds ratio $(95 \% \mathrm{Cl}) ; \mathrm{P}$ value & \multicolumn{2}{|c|}{2.70 (1.18 to 6.21$) ; 0.019 \dagger$} & \multicolumn{2}{|c|}{5.36 (1.24 to 23.18); $0.025 \dagger$} & \multicolumn{3}{|c|}{$3.46(1.84,6.52) ;<0.001 \ddagger$} \\
\hline
\end{tabular}

*Numbers of case-control pairs corresponding to presence/absence of SCE: Alzheimer's disease $+/+(n=3),-/-(n=39),+/-(n=29),-/+(n=9)$, discordance rate $=48 \%$; vascular dementia $+/+$ $(\mathrm{n}=7),-1-(\mathrm{n}=47),+-(\mathrm{n}=24),-/+(\mathrm{n}=5)$, discordance rate $=35 \%$.

†Adjusted for cardiovascular risk factors (significant at $10 \%$ level) in table 3.

$\ddagger$ Adjusted for age, sex, and cardiovascular risk factors (significant at $10 \%$ level) in table 3. 
Research

Table 5 Comparison of spontaneous cerebral emboli (SCE) positive and SCE negative participants. Values are numbers (percentages) unless stated otherwise

\begin{tabular}{|c|c|c|c|c|c|c|}
\hline \multirow{2}{*}{ Characteristic } & \multicolumn{3}{|c|}{ Dementia* } & \multicolumn{3}{|c|}{ Controls } \\
\hline & SCE positive $(n=65)$ & SCE negative $(n=102)$ & $P$ value & SCE positive $(\mathrm{n}=21)$ & SCE negative ( $\mathrm{n}=124)$ & $P$ value \\
\hline Mean (SD) age (years) & $76.7(7.8)$ & $76.0(6.6)$ & 0.53 & $76.5(6.8)$ & $76.5(6.5)$ & 1.0 \\
\hline Male sex & $37(57)$ & $51(50)$ & 0.38 & $9(43)$ & $69(56)$ & 0.28 \\
\hline Mean (SD) MMSE score & $21.1(4.4)$ & $21.9(5.1)$ & 0.29 & $28.2(1.6)$ & $28.6(1.4)$ & 0.21 \\
\hline \multicolumn{7}{|l|}{ Carotid disease: } \\
\hline$>50 \%$ & $10(15)$ & $15(15)$ & 0.90 & $8(38)$ & $23(19)$ & 0.06 \\
\hline$>70 \%$ & $3(5)$ & $2(2)$ & 0.32 & $4(19)$ & $6(5)$ & 0.023 \\
\hline \multicolumn{7}{|c|}{ Venous to arterial circulation shunt: } \\
\hline "Significant" & $22(34)$ & $29(28)$ & 0.46 & $4(19)$ & $28(23)$ & 0.72 \\
\hline "Major" & $11(17)$ & $18(18)$ & 0.90 & $2(10)$ & $16(13)$ & 0.66 \\
\hline \multicolumn{7}{|c|}{ Mean (SD) blood pressure $(\mathrm{mm} \mathrm{Hg})$ : } \\
\hline Systolic & $143.1(26.0)$ & $140.9(27.8)$ & 0.62 & $150.5(24.4)$ & $143.6(22.9)$ & 0.22 \\
\hline Diastolic & $74.3(14.3)$ & $76.8(13.1)$ & 0.26 & $86.0(11.9)$ & $77.4(14.5)$ & 0.013 \\
\hline \multicolumn{7}{|c|}{ Mean (SD) lipid concentrations (mmol/l): } \\
\hline Cholesterol & $5.42(1.23)$ & $5.27(0.99)$ & 0.39 & $5.32(1.13)$ & $5.41(1.06)$ & 0.73 \\
\hline HDL cholesterol & $1.37(0.39)$ & $1.34(0.40)$ & 0.66 & $1.39(0.33)$ & $1.42(0.49)$ & 0.80 \\
\hline LDL cholesterol & $3.34(1.05)$ & $3.14(0.80)$ & 0.17 & $3.03(1.05)$ & $3.20(0.91)$ & 0.45 \\
\hline Triglycerides† & $1.36(0.9-1.9)$ & $1.45(1.0-1.9)$ & 0.37 & $1.62(1.2-2.2)$ & $1.63(1.1-2.3)$ & 0.94 \\
\hline MI or angina: & $12(19)$ & $18(18)$ & 0.86 & $8(38)$ & $22(18)$ & 0.03 \\
\hline $\mathrm{Ml}$ & $4(6)$ & $8(8)$ & 0.68 & $3(14)$ & $9(7)$ & 0.28 \\
\hline Angina & $9(14)$ & $13(13)$ & 0.81 & $6(29)$ & $17(14)$ & 0.09 \\
\hline Stroke or TIA: & $21(32)$ & $36(35)$ & 0.69 & $9(43)$ & $9(7)$ & $<0.001$ \\
\hline Stroke & $7(11)$ & $11(11)$ & 1.0 & $5(24)$ & $3(2)$ & 0.001 \\
\hline TIA & $18(28)$ & $33(32)$ & 0.52 & $6(29)$ & $6(5)$ & $<0.001$ \\
\hline$\overline{P V D}$ & $16(25)$ & $21(21)$ & 0.54 & $7(33)$ & $26(21)$ & 0.22 \\
\hline Diabetes & $3(5)$ & $7(7)$ & 0.55 & $2(10)$ & $5(4)$ & 0.28 \\
\hline Smoking (current) & $9(14)$ & $18(18)$ & 0.66 & $2(10)$ & $18(15)$ & 0.79 \\
\hline Antiplatelet drugs & $29(45)$ & 42 (41) & 0.66 & $12(57)$ & $32(26)$ & 0.004 \\
\hline
\end{tabular}

$\mathrm{HDL}=$ high density lipoprotein; $\mathrm{LDL}=\mathrm{low}$ density lipoprotein; $\mathrm{Ml}=$ myocardial infarction; MMSE=mini-mental state examination; PVD=peripheral vascular disease; TIA=transient ischaemic attack. ${ }^{*}$ Alzheimer's disease or vascular dementia.

†Geometric mean (interquartile range).

This is unlikely to have biased our results, as we recorded transcranial Doppler sessions for subsequent blind analysis. We were also unable to compare data on health between participants and non-participants (those who refused consent), as we would have needed consent to get this information. Although we asked about memory problems, and used an accepted cut-off score on the mini-mental state examination to exclude controls with significant cognitive impairment, ${ }^{20}$ controls did not have further neuropsychological assessment to diagnose or exclude early dementia.

\section{Cardiovascular risk factors}

The distribution of cardiovascular risk factors was similar in dementia patients and their controls. Only a history of stroke or transient ischaemic attack was more common in vascular dementia than in controls and Alzheimer's disease patients. The likely explanation is that a history of cerebrovascular symptoms and infarcts on brain imaging would influence the clinician to diagnose vascular dementia rather than Alzheimer's disease. As the diagnosis of vascular dementia would usually lead to the prescription of antiplatelet drugs, this factor was also associated with vascular dementia.

This study is the first to show an association between SCE and dementia. The similar frequency of emboli in both types of dementia suggests a common cause and shared pathophysiology. We are investigating whether SCE predict future cognitive decline in both dementia patients and controls.

\section{Conclusion}

Spontaneous cerebral emboli were significantly more frequent in both Alzheimer's disease and vascular dementia patients than in sex and age matched controls. They may be a potentially preventable or treatable cause of dementia.

We are grateful for the contribution made by the patients, their carers, and the elderly people who volunteered to help as controls.

Contributors: NP participated in the study design, assessment of dementia, statistical analysis, and writing the manuscript. KJD did venous to arterial circulation shunt testing and commented on the manuscript. JH coordinated the study, validated transcranial Doppler monitoring for spontaneous cerebral emboli, and commented on the manuscript. JM did the statistical analysis and commented on the manuscript. GM participated in study design and commented on the manuscript. $\mathrm{AB}$ participated in devel-

\section{What is already known on this topic}

Considerable overlap exists between Alzheimer's disease and vascular dementia

Vascular risk factors may be involved in the causation of both conditions

Spontaneous cerebral emboli are associated with increased risk of stroke and cognitive impairment in patients having carotid or cardiac surgery

\section{What this study adds}

Spontaneous cerebral emboli are significantly associated with both Alzheimer's disease and vascular dementia and may be involved in the pathophysiology of both conditions

Spontaneous cerebral emboli may represent potentially preventable or treatable cause of both types of dementia 


\section{Research}

oping the hypothesis, the study design, assessment of dementia, and writing the manuscript. CMcC conceived the hypothesis and participated in the study design and writing the manuscript. $\mathrm{CMcC}$ is the guarantor. Jane Byrne independently validated the diagnosis of dementia. Jenny Shuttleworth, Sophie Holliday, and Zoe Bonner collected the data. Joanne Wren (funded by the Alzheimer's Society) completed data validation.

Funding: The study was funded by the Wellcome Trust. The researchers were independent of the funding body, who played no role in the analysis or writing of the manuscript.

Competing interests: None declared.

Ethical approval: Local research ethics committees in Manchester and Stockport: South and North Manchester LREC reference SOU/98/132; Central Manchester LREC reference CEN/00/027/CA; Stockport LREC reference EE/SR/MREC2029.

1 Stewart R, Prince M, Mann A. Vascular risk factors and Alzheimer's disease. Aust N ZJ Psychiatry 1999;33:809-13

2 Skoog I, Kalaria RN, Breteler MMB. Vascular factors and Alzheimer disease. Alzheimer Dis Assoc Disord 1999;13:S106-14

3 Hofman A, Ott A, Breteler MM, Bots ML, Slooter AJ, van Harskamp F. Atherosclerosis, apolipoprotein E, and prevalence of dementia and Alzheimer's disease in the Rotterdam study. Lancet 1997;349:151-4.

4 Hutchinson S, Riding G, Coull S, McCollum CN. Are spontaneous cerebral microemboli consistent in carotid disease? Stroke 2002;33:685-8.

5 Deklunder G, Roussel M, Lecroart JL, Prat A, Gautier C. Microemboli in cerebral circulation and alteration of cognitive abilities in patients with mechanical prosthetic heart valves. Stroke 1998:29;1821-6.

6 Fearn SJ, Pole R, Wesnes K, Faragher EB, Hooper TL, McCollum CN. Cerebral injury during cardiopulmonary bypass: emboli impair memory. J Thorac Cardiovasc Surg 2001:121:1150-60

7 Russell D. Cerebral microemboli and cognitive impairment. J Neurol Sci 2002;203-204:211-4

8 Stygall J, Newman SP, Fitzgerald G, Mulligan K, Arrowsmith JE, Pugsley W, et al. Cognitive change 5 years after coronary artery bypass surgery. Health Psychol 2003;22:579-86.

9 Sliwka U, Job FP, Wissuwa D, Diehl RR, Flachskampf FA, Hanrath P, et al. Occurrence of transcranial Doppler high-intensity transient signals in patients with potential cardiac sources of embolism: a prospective study. Stroke 1995;26:2067-70.

10 Anzola GP. Clinical impact of patent foramen ovale diagnosis with transcranial Doppler. Eur J Ultrasound 2002;16:11-20.

11 Ott A, Breteler MM, de Bruyne MC, van Harskamp F, Grobbee DE, Hofman A. Atrial fibrillation and dementia in a population-based study. Stroke 1997;28:316-21.

12 Lechat P, Mas JL, Lascault G. Prevalence of patent foramen ovale in patients with stroke. N Engl J Med 1988;318:1148-52

13 Webster MW, Chancellor AM, Smith HJ, Swift DL, Sharpe DN, Bass NM, et al. Patent foramen ovale in young stroke patients. Lancet 1988;ii:11-2

14 Riding G, Rao S, Hutchinson S, Kilic J, Lovell M, McCollum C. Cerebral emboli during hip and knee replacement: the role of venous to arterial shunting [abstract]. Br J Surg 2001;88:745.

15 Meier B, Lock JE. Contemporary management of patent foramen ovale. Circulation 2003;107:5-9.

16 Sastry S, MacNab A, Daly K, Ray SG, McCollum CN. Transcranial Doppler or transoesophageal echocardiography for the detection of venous-to-arterial circulation shunts [abstract]. Heart 2002;88(suppl IV):32.
17 Purandare N, Welsh S, Hutchinson S, Riding G, Burns A, McCollum C. Cerebral emboli and paradoxical embolisation in dementia: a pilot study. Int J Geriatr Psychiatry 2005;20:12-6.

18 McKhann G, Drachman D, Folstein M, Katzman R, Price D, Stadlan EM. Clinical diagnosis of Alzheimer's disease: report of the NINCDS-ADRDA Work Group under the auspices of Department of Health and Human Services Task Force on Alzheimer's Disease. Neurology 1984;34:939-44.

19 Roman GC, Tatemichi TK, Erkinjuntti T, Cummings JL, Masdeu JC, Garcia JH, et al. Vascular dementia: diagnostic criteria for research studies. Report of the NINDS-AIREN International Workshop. Neurology 1993;43:250-60.

20 Folstein MF, Folstein SE, McHugh PR. Mini-mental state: a practical method for grading the cognitive state of patients for the clinician. Psychiatry Res 1975;12:189-98.

ing the cognitive state of patients for the clinician. Psychiatry Res 1975;12:189-98. Consensus on microembolus detection by TCD. Stroke 1998;29:725-9.

22 Consensus Committee of the Ninth International Cerebral Hemodynamic Symposium. Basic identification criteria of Doppler microembolic signals. Stroke 1995;26:1123.

23 Sidhu PS, Allen PL. Ultrasound assessment of internal carotid artery stenosis. Clin Radiol 1997;52:654-8.

24 Di Tullio M, Sacco RL, Venketasubramanian N, Sherman D, Mohr JP, Homma S. Comparison of diagnostic techniques for the detection of a patent foramen ovale in stroke patients. Stroke 1993;24:1020-4.

25 Nygren AT, Jogestrand T. Detection of patent foramen ovale by transcranial Doppler and carotid duplex ultrasonography: a comparison with transoesophageal echocardiand carotid duplex ultrasonography:
ography. Clin Physiol 1998;18:327-30.

26 Droste DW, Silling K, Stypmann J, Grude M, Kemeny V, Wichter T, et al. Contrast transcranial doppler ultrasound in the detection of right-to-left shunts: time window and threshold in microbubble numbers. Stroke 2000;31:1640-5.

27 Jauss M, Zanette E. Detection of right-to-left shunt with ultrasound contrast agent and transcranial Doppler sonography. Cerebrovasc Dis 2000;10:490-6.

28 Hagan PT, Scholz DG, Edwards WD. Incidence and size of patent foramen ovale during the first 10 decades of life: an autopsy study of 965 normal hearts. Mayo Clin Proc 1984;59:17-20.

29 Stork JL, Kimura K, Levi CR, Chambers BR, Abbott AL, Donnan GA. Source of microembolic signals in patients with high-grade carotid stenosis. Stroke 2002;33:2014-8.

30 Meier B. Closure of patent foramen ovale: technique, pitfalls, complications, and follow up. Heart 2005;91:444-8.

(Accepted 7 March 2006)

doi 10.1136/bmj.38814.696493.AE

Department of Psychiatry, University of Manchester, Manchester

Nitin Purandare senior lecturer in old age psychiatry

Alistair Burns professor of old age psychiatry

Academic Surgery Unit, University of Manchester

Kevin J Daly lecturer in surgery

Jayne Hardicre study coordinator

Charles McCollum professor of surgery

South Manchester University Hospitals NHS Trust, Manchester

Julie Morris head of medical statistics

School of Epidemiology and Health Sciences, University of Manchester, Manchester M13 9PT

Gary Macfarlane professor of epidemiology

Correspondence to: C McCollum cnmcc@manchester.ac.uk 